\title{
Urbanismo na Era Digital: desenho urbano e processos digitais
}

\author{
Urbanism in the Digital Age: urban design and digital processes \\ - Isabel Cristina da Silva Lima \\ Universidade São Judas Tadeu, Brasil \\ Maria Carolina Maziviero \\ Universidade São Judas Tadeu, Brasil \\ isabel_lima_2@hotmail.com \\ mcarolmazi@hotmail.com \\ - Fernando Toledo Silva \\ Universidade São Judas Tadeu, Brasil \\ fernandousjt@outlook.com
}

\begin{abstract}
The paper analyzes the theoretical and methodological approach of contemporary urban design associated to digital processes. This new approach to urban studies is based on parametric design systems in which the focus of interest is not in the form itself, but the parameters that generate it. As an alternative to traditional design system, this methodology provides greater control of the entire process, since the parameters can be changed during all stages of the work. Thus, this paper presents some cases to understand the advantages and disadvantages of using this new way of designing on urban scale.
\end{abstract}

Keywords: Urban Projects, Digital Thought, Inventory, Generative Systems, Design Process

\section{Introdução}

Os avanços computacionais do último quartel do século $\mathrm{XX}$, introduziram novas tecnologias no processo projetual e tornaram necessárias uma revisão da forma tradicional de trabalho de arquitetos e designers (KOVALERIC, 2003). Essa nova maneira de projetar consiste na capacidade de manipular informações digitalmente, e a partir deste ponto, formular análises e simulações sobre aspectos quantitativos ou qualitativos do projeto. Assim, essa metodologia amplia as possibilidades de simulações de diferentes estratégias para solucionar problemas nos mais variados campos, desde os de caráter mais técnicos, como acústica, conforto térmico, estruturas, fluxos, entre outros, assim como elementos da esfera socioeconômica, cultural e espacial.

O objetivo deste artigo é compreender e analisar esse procedimento teórico e metodológico contemporâneo no Urbanismo, que parece ainda um pouco alheio as possibilidades que a tecnologia avançada oferece. Portanto, traça-se aqui uma breve discussão entrelaçando conceitos de diferentes autores do campo dos estudos urbanos para, a partir deles, pensar o potencial de abrangência e integração entre desenho urbano e processos digitais. Atualmente, delineiase uma nova corrente de desenho urbano fundamentada, principalmente, em sistemas de desenho paramétrico. Seu objetivo é buscar maior flexibilidade e variedade de modelos, com maior controle de todo processo projetual. $\mathrm{O}$ desenho paramétrico, já amplamente utilizado nas indústrias aeroespacial e automotiva, tem como foco de interesse não a forma em si, mas os parâmetros que a geram. Essa técnica de desenho alinhada a processos digitais vem sendo, pouco a pouco, transferida para a arquitetura e, em menor grau, para o urbanismo (AMORIM e CANUTO, 2009).

\section{Processos digitais e projeto urbano}

A incorporação de sistemas generativos à metodologia de projeto urbano parece ser mais adequada a complexidade da cidade contemporânea, sobretudo se pensarmos na porção informal destas cidades. Romano e Tonoli (2012) desenvolveram um método para identificar a lógica da cidade informal, reconhecendo suas complexas relações. Destes aglomerados urbanos de surgimento espontâneo, resultam problemas de difícil solução para projetos de intervenção urbana. Há uma incompatibilidade entre a lógica complexa desse território e a reticula tradicional, amplamente difundida pelos projetos urbanos modernistas. A partir da investigação sobre a lógica de expansão da cidade informal foi gerado um script paramétrico que se adaptasse a realidade daquele determinado local. Após a identificação de quais agentes transformadores atuavam como forças de transformação, os autores compreenderam a complexidade destes aglomerados. Em áreas informais, todos os elementos que compõem o território estão diretamente imbricados e encontram-se em 
situação de vulnerabilidade, sofrendo constante modificações e reconfigurando-se conforme as circunstâncias.

Romano e Tonoli (2012) defendem que, dada a formação desses assentamentos baseada em adaptações em função das necessidades da comunidade, o espaço resultante da ocupação deve ser capaz de se adaptar às novas exigências e abrigar variados programas de uso. Portanto, segundo eles, intervenções nessas áreas que não levem em conta tal complexidade, fatalmente fracassam. A aplicação do algoritmo resultante deste processo investigativo permitiu que os autores concluíssem que a utilização de uma metodologia projetual com mais recursos analíticos e mais flexível permite um resultado mais próximo do que, de fato, é necessário para a complexa organização das áreas informais das cidades brasileiras.

O trabalho de Mata (2013) também aponta vantagens do uso de ferramentas computacionais aliadas a atividade projetual. A principal delas seria a possibilidade de gerar uma variedade maior de soluções para um mesmo problema, criando condição mais favorável a experimentação de diversos cenários. Em seu trabalho, a autora analisou diferentes tipologias de arquitetura apoiadas em processos digitais, destrinchando a metodologia adotada em cada projeto. Demonstrou como o uso do desenho paramétrico permite o gerenciamento de informações e a integração entre diferentes disciplinas, em um regime colaborativo de continuo desenvolvimento projetual, "para os projetistas estas tecnologias proporcionam a oportunidade de dispor de outras áreas e responsabilidades, tais como, a captura de dados, avaliação de dados, otimização das soluções e simulação dos resultados planejados" (MATA, pg.11, 2013). Assim, a parametria aplicada ao urbanismo e apoiada em ferramentas computacionais amplia as possibilidades de simulação de diferentes soluções com maior rapidez, tornando o processo mais dinâmico.

\section{Sintaxe Espacial como ferramenta de análise}

Sob outro aspecto, a Sintaxe Espacial, ou Teoria da Lógica Social do Espaço defende que o espaço como aglomeração urbana em seu estado inicial, em sua origem, já nasce social, uma vez que apresenta em sua configuração espacial os aspectos sociais e culturais de seus fundadores. Desta forma, essa teoria pode ser considerada uma teoria socioespacial, ou seja, não é seu objetivo lidar com a volumetria arquitetônica ou com elementos urbanos isolados, ou se fixar em seus aspectos formais, funcionais ou estéticos, mas sim classificálos como elementos articuladores entre espaço construído e a sociedade. Desenvolvida a partir dos anos 1970, na University College London (UCL) por Bill Hillier e seus contemporâneos, tornou-se amplamente conhecida a partir de 1984, quando Bill Hillier e Jullienne Hanson publicaram o livro The Social Logic of Space, seguido por Space is the Machine, de 1996.

Através de técnicas de análises, a Sintaxe Espacial descreveu a interação entre espaço e sociedade, mostrandose como uma importante ferramenta no estudo da configuração urbana. Possui duas categorias de abordagens: uma analítica e outra explicativa. São princípios da Sintaxe Espacial principalmente os aspectos relacionais entre espaço e sociedade. A Teoria entende que o espaço não é apenas o contexto inerte do espaço construído, pois sofre influência da sociedade assim como também influencia-a. Assim, a arquitetura pode ter a função de organizar os espaços para a vida em sociedade, promovendo o encontro e a urbanidade - e o espaço construído é a resultante do modo como as culturas se estruturam fisicamente. Desta forma, a configuração das edificações no espaço e como comportam-se em relação à paisagem e à cidade são importantes elementos a serem analisados. A maneira pela qual as pessoas se apropriam ou fazem uso do espaço também fazem parte do escopo da Sintaxe Espacial, no sentido de que a arquitetura como elemento social permite o encontro interpessoal, planejado ou não. A principal preocupação está na abordagem sistemática dos objetos, não soltos no espaço, mas sua relação com o todo, com a visão relacional e global.

Os estudos de Hillier classificaram vias com maior número de conexões como rasas, ou mais integradas, em contraposição as mais profundas, ou menos integradas, isto é, mais segregadas dentro do sistema. Como metodologia, transformou a malha urbana em linhas axiais que representavam o movimento natural. Utilizou, então, não o ambiente geográfico, mas o topológico, para o qual o comprimento da linha é menos importante do que suas propriedades relacionais. Dessa forma, Hillier alinhou o conceito de topologia à Sintaxe Espacial ao lidar com o espaço e os fluxos gerados desde o ponto de vista qualitativo, e não quantitativo. Transformações topológicas, primeiramente, afetam a relação de estruturas e, depois, suas formas.

Outro caso interessante de uso da Sintaxe Espacial, também em Londres, foi a intervenção na praça Trafalgar Square, em 1998, pela equipe Foster and Partners, Halcrow Fox, Civic Design Partnership e Davis Langdon and Everest. Através desse estudo foi identificado que a população evitava utilizar a praça com medo da violência, e que os turistas não conseguiam atravessar em direção ao Parlamento. Depois da análise, feita com o Mapa Axial e estudos do Movimento Natural, a equipe propôs como solução uma escadaria que restabeleceu o percurso natural do pedestre. A maior acessibilidade possibilitada pela introdução da escadaria transformou a praça em local de encontro social e turismo, movimentado e convidativo.

O mapa axial é derivado de uma base cartográfica digital, na qual são traçados segmentos de linhas ao longo dos eixos viários. Desta forma, definidos os maiores eixos em um menor número de linhas possível, elimina-se a base cartográfica, restando apenas as linhas axiais, ou seja, tem-se um mapa axial. A partir daí, esse mapa é inserido em um programa computacional que transforma esses segmentos de linhas em valores numéricos, formando uma matriz. Essa análise demonstra, em uma escala de cores, o índice de integração, para o qual a cor vermelha representa os eixos mais integrados do 
sistema, seguida pelas cores laranja, verde, azul claro e por fim, azul escuro, que representa as regiões ou eixos mais segregados no sistema em estudo. Pela análise do mapa também é possível demarcar um núcleo de integração, normalmente identificado como um centro significativo de atividades ou como centro ativo com potencial para ser explorado.

Holanda, expoente brasileiro na pesquisa sobre Sintaxe Espacial, criou um sistema para avaliar se um ambiente urbano apresenta, em sua configuração, mais formalidade ou mais urbanidade. Para medir o grau de urbanidade do espaço, estabeleceu um sistema pautado em fórmulas matemáticas resultantes de parâmetros que, processados pelo computador, formam uma matriz e são convertidos em valores. Considerando uma escala de 0 à 5 , cidades mais próximas ao 0 são cidades mais formais e aquelas mais próximas ao 5 são menos formais e, portanto, contém mais urbanidade. Como exemplo ele considera Brasília como cidade formal, onde há segregação de usos, e a configuração leva a baixos índices de integração. Por outro lado, centros históricos com traçado irregular e mistura de usos propiciam uma maior possiblidade de encontros, contendo mais urbanidade em sua configuração.

Assim, associação dessa poderosa técnica analítica com a computação, por meio dos processos digitais contemporâneos, vem ampliando significativamente a capacidade decruzamento de múltiplas variáveiscontidasno espaço urbano. A inserção de ferramentas computacionais incide consideravelmente na variável tempo, minimizando ou reduzindo a espera nos procedimentos operativos. Ainda assim, há outros desafios a respeito da integração entre novas tecnologias e a Sintaxe Espacial no processo de projeto na escala urbana como, por exemplo, a codificação de aspectos qualitativos.

\section{Frei Otto e o sistema de fluxos}

As pesquisas de Frei Otto e seus contemporâneos também relacionavam o desenho urbano às formas e comportamentos orgânicos. Em 1961, Frei Otto criou um grupo de pesquisa sobre construção e biologia na Universidade Técnica de Berlim. O trabalho cooperativo entre arquitetos, engenheiros e biólogos marcou significativamente o desenvolvimento de suas pesquisas, vinculando, por exemplo, conhecimentos de tendas, e outras estruturas leves a estruturas e formas biológicas. Otto (2011) demonstrou, em processos generativos e com a utilização de algoritmos, a aplicabilidade desses princípios, buscando provar que a dinâmica das ocupações e conexões urbanas necessitava de outro olhar. Baseandose nos padrões encontrados na natureza, desenvolveu não só os famosos sistemas estruturais de malhas tensionadas, mas também estudos de caminhos mínimos através de experimentos simples, por exemplo, com fios de algodão entrelaçados. As linhas de seus experimentos com fios de algodão que organizam-se e aproximam-se naturalmente quando molhadas, representavam uma malha urbana de traçado irregular, que se adapta melhor aos fluxos, conexões, condições do terreno e outros aspectos.
Otto divide o sistemas de fluxos encontrados na natureza em dois segmentos principais: os sistemas de fluxos no mundo da natureza não-viva, e aquelas da natureza viva. O primeiro, refere-se aos fluxos de água, descargas elétricas, deslizamento de neve, caminhos dos ventos (tornados), movimentação da crosta terrestre visível nas fendas formadas, ondas de som, e até a irradiação de luz. Mesmo existindo em toda parte na natureza, esse sistema não serve à um propósito específico. Já os sistemas de fluxos da natureza viva são muito variados e utilizam aquelas da natureza não-viva para transportarem o que necessitam. Como exemplo, o sistema de transporte de fluidos nas plantas utiliza amplamente o momento, atrito, e forças externas como vento, neve e água para recolher minerais.

Em relação aos assentamentos humanos, o autor também define diferentes sistemas de fluxos que ocorrem por diferentes motivos, em diferentes escalas, sempre tendo como base a lei natural do menor esforço para vencer os caminhos. Um desses sistemas, definido por Otto, é o sistema de fluxo generativo. Esse sistema diz respeito a uma ocupação que ocorre em etapas diferentes, com adição de pontos sequenciais. Nela, os novos pontos se conectam por meio de caminhos mais curtos e de forma direta aos caminhos antigos. Essas ligações são, geralmente, perpendiculares ou em " $\mathrm{T}$ ".

Recentemente, simulações chamadas Hair Systems tem atualizado os estudos de fluxos e de caminhos mínimos de Frei Otto por meio da computação. Todas as linhas, que representam fluxos, podem ser tratadas como verdadeiras geometrias, e as configurações das curvas pode ser alteradas de forma dinâmica. Ao sistema de fluxos são atribuídos uma série de atributos que, quando manipulados digitalmente, afetam todo o sistema.

\section{Considerações finais}

Os assentamentos humanos espontâneos são resultado de um processo único de crescimento, não aplicável em outro lugar, e que tomam como determinantes os aspectos físicos naturais e pontos de atração (Igrejas, largos, praças). Não só áreas informais, mas cidades onde o território - a partir das suas condições geomorfológicas, orientou o desenvolvimento urbano, tais como Ouro Preto ou partes de Salvador e Rio de Janeiro, seguem também essa lógica não-linear, resultando em sistemas complexos com traçados não ortogonais. Tais formações espontâneas são, portanto, influenciadas pelas condições do meio, e sua forma urbana é uma adaptação e um resultado das forças a que estão sujeitas.

Assim, para que um projeto de intervenção nesses assentamentos, informais ou não, sejam mais aderentes ao local, é necessário projetar a partir de sua lógica intrínseca, das dinâmicas de interação entre as múltiplas camadas sobrepostas que compõem o território. Para isso, é imprescindível compreende-las e decodifica-las.

As mudanças de paradigma trazidas pelas tecnologias emergente tem se expandido para diversas áreas. O urbanismo, enquanto teoria e prática, mostra-se um campo 
capaz de receber essa abordagem alternativa, que compreenda melhor a complexidade da cidade e estabeleça relações mais propícias ao contexto. A partir do desenvolvimento dessa pesquisa, concluiu-se que o uso de processos digitais em projetos urbanos é possível e capaz de suprir as necessidades de um programa tão complexo quanto o de uma cidade. A América Latina forma um vasto campo de experimentação para que se aplique essa nova metodologia, considerando-se a quantidade de áreas informais nas cidades. Especificamente sobre o Brasil, atesta-se ainda número considerável de cidades herdeiras de traçados urbanos portugueses, que se articulam fortemente com as características físicas dos sítios em que são implantados, especialmente com a topografia.

Ainda que a arquitetura, na escala do edifício, venha articulando-se, pouco a pouco, com os avanços tecnológicos recentes, o projeto na escala urbana parece ainda não incorporá-los completamente. A experimentação é essencial para o avanço da disciplina e permite que vincular o projeto à produção, dando um salto na evolução das abordagens e na resolução dos problemas.

\section{Referências}

AMORIM, Luiz; CANUTO, Robson. O urbanismo paramétrico de Zaha Hadid: emergências, limites e perspectivas. In: Anais do IV Projetar. 2009.

BATTY, Michael. Cities and Complexity: Understanding Cities with Cellular Automata, Agent-Based Models, and Fractals.
Cambridge, Cambridge University Press, 2005.

HANSON, Julienne; HILLIER, Bill. The social logic of space. Londres: Cambridge University, 1984.

HOLANDA, Frederico; FARRET, Ricardo L.; GONZALES, Suely Franco Netto; KOHLSDORF, Maria Elaine. O Espaço da cidade: contribuição à análise urbana. São Paulo: Projeto, 1985. HOLANDA, Frederico, O espaço de exceção. Brasilia: Editora Universidade de Brasília, 2002

HOLANDA, Frederico, Arquitetura e urbanidade, São Paulo: ProEditores Associados, 2003

HOLANDA, Frederico. Ordem e Desordem: Arquitetura e Vida Social. Brasília: Editora FRBH, 2012.

HOLANDA, Frederico. 10 Mandamentos da Arquitetura. Brasília: Editora FRBH, 2013.

KOLAREVIC, B. Architecture in digital age; Design and manufacturing. New York: Spon Press, 2003.

MATA, Maria João Gomes. Proposta para uma metodologia de Projeto Paramétrico Integrado. Dissertação de mestrado. Instituto Superior Técnico, Lisboa, 2013.

OTTO, Frei. Occupying and Connecting: thoughts on territories and spheres of influence with particular reference to human settlement. Stuttgart: Edition Axel Menges, 2011.

ROMANO, E.; TONOLI, G. Código genético das Favelas: identificaçao, interpretação e aplicação. In: XVII Seminario da APEC - Associação dos Pesquisadores e Estudantes Brasileiros na Catalunha, 2012, Barcelona. Anais do XVII Seminário da APEC. Barcelona: APEC, 2012. v. 1. 